\title{
Modelling of electrical and mechanical phenomena in induction motors with air-gap eccentricity
}

\author{
D. Mazur ${ }^{1}$ and M. Trojnar ${ }^{1}$ \\ ${ }^{1}$ Department of Electrical and Computer Engineering Fundamentals \\ Rzeszow University of Technology, \\ ul. W. Pola 2, 35-959 Rzeszów (Poland) \\ phone:+48 17 8651298, fax:+48 17 8542088, e-mail: mazur@prz.rzeszow.pl, trojnar@prz.rzeszow.pl
}

\begin{abstract}
Parasitic torque harmonics and stator current harmonics to rotational speed of the asynchronous motor are presented in this paper. The study of torque harmonics and stator current harmonics has been carried out with the computer simulation. The obtained results on both $2 \mathrm{D}$ and $3 \mathrm{D}$ graphs are presented to the rotational speed of the electric motor. Parameters for each particular harmonics have been found with these graphs. These graphs help to identify the origins of these harmonics as the co-action of the MMF of the stator current and the magnetic induction from the rotor in the airgap. Particular attention has been paid to how iron saturation influences these harmonics. The harmonics under study (in quantity of 18) has been taken under consideration, because they exhibited their presence in the mentioned above graphs as the functions of speed. Their origin has been also indicated on the graphs made as an extension of the Kluszczynski analytic/graphic diagrams [6].
\end{abstract}

\section{Key words}

A parasitic torques, asynchronous motor, stator current harmonics and torque harmonics, rotor eccentricity

\section{Introduction}

The model described in [2,7] was applied for the calculations. To consider the skew of the rotor bars, the whole machine is divided along its whole length into 7 elementary machines of straight, but offset against each other bars. The magnetic field in the cross-section of each elementary machine is calculated with finite elements method. The iron saturation of the magnetic circuit is reflected with the polynomial relation of the magnetic field strength to the magnetic induction. A 9-th order polynomial is used. For the calculation of the currents and torques to time for the asynchronous motor type Sg90S-4 with aluminium cage manufactured with Electric Motor Manufacturing (F.S.E.) "TAMEL" in Tarnów, Poland, presented previously method has been used. The output of the motor is $P=1.1 \mathrm{~kW}$, rated voltage is $\mathrm{U}_{\mathrm{N}}=380$ volts and rated current $\mathrm{I}_{\mathrm{N}}=2.8 \mathrm{amps}$, rated speed is $\mathrm{n}=1415 \mathrm{rpm}$, the stator slot quantity is 36 and the rotor slot quantity is $28,26,24$. The length of the machine is $0,7 \mathrm{~m}, \cos \varphi=0.8$. The computational program presented here has also produced spatial harmonics of radial forces and electromagnetic torque of higher order. Failures bar or ring fracture as well as static, dynamic and mixed eccentricity can also be considered.

\section{Algoritm calculation model of induction motor by 2.5D FEM}

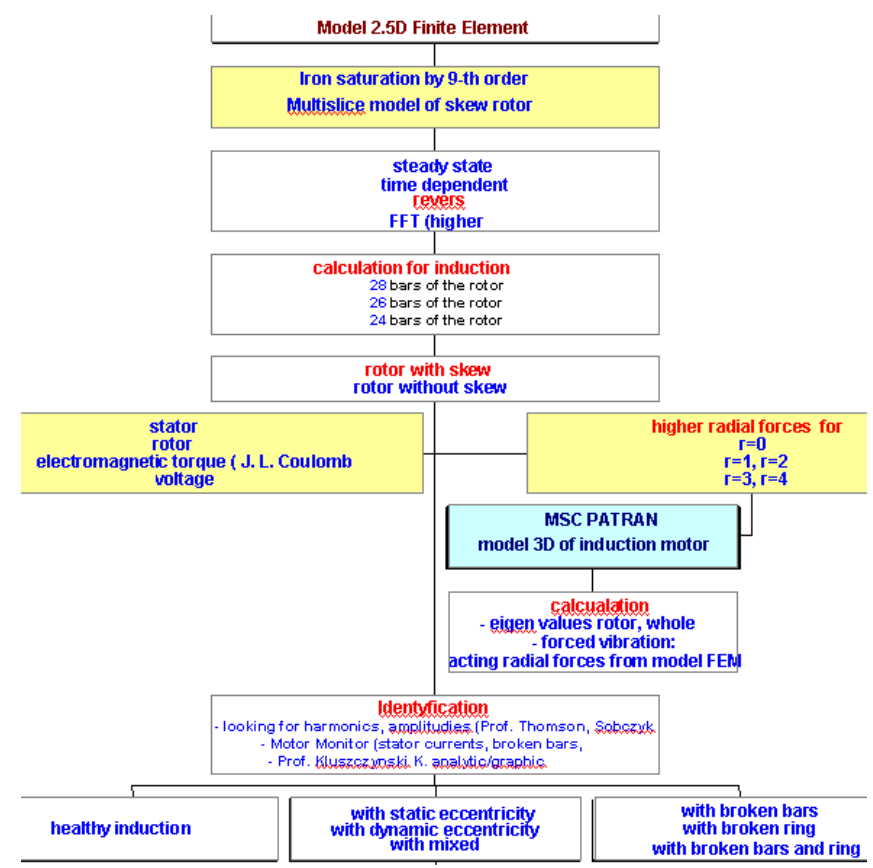

\section{Identification of the sources of the generation of the parasitic torque harmonics}

The computer simulations of the $2.5 \mathrm{D}$ model using the finite elements method of the asynchronous machine were performed first. To consider a rotor bar skew, the motor model was divided into 7 elementary machines of straight but offset against each other bars. The rotational speed of the motor was changing with the acceleration of $40 \mathrm{rad} / \mathrm{s} 2$ or $10 \mathrm{rad} / \mathrm{s} 2$. The best results for the harmonics analysis were obtained at lower speeds. But when the computational speed was considered the speed of $20 \mathrm{rad} / \mathrm{s} 2$ appeared the most suitable. The electromagnetic torque and current values over time obtained this way are subject to harmonic analysis with FFT method $[3,12,13]$. 
The analysis was performed for various rotational speeds of the motor. The results are indicated with dots in Fig.1.

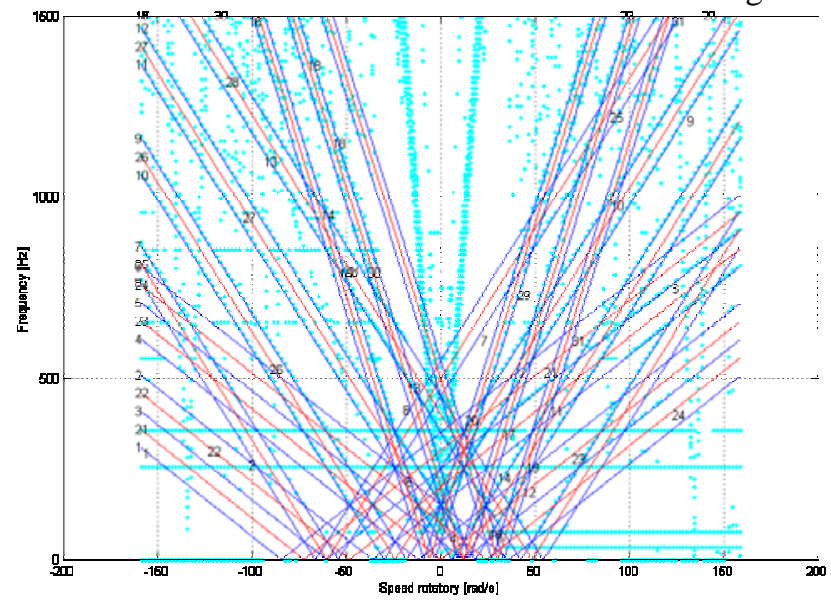

Fig.1. Frequency for the most significant harmonics of the torque (red) and stator current (blue) as a function of the rotational speed of the induction motor with 26 rotor bars and static eccentricity.

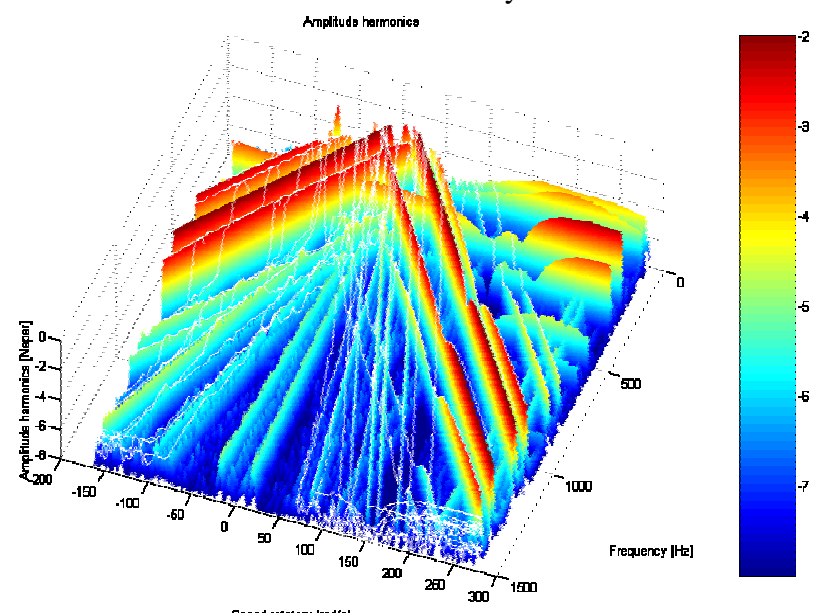

Fig.2. Module parasitic harmonics torque as a function of the rotational speed of the induction motor with 28 rotor bars and dynamic eccentricity.

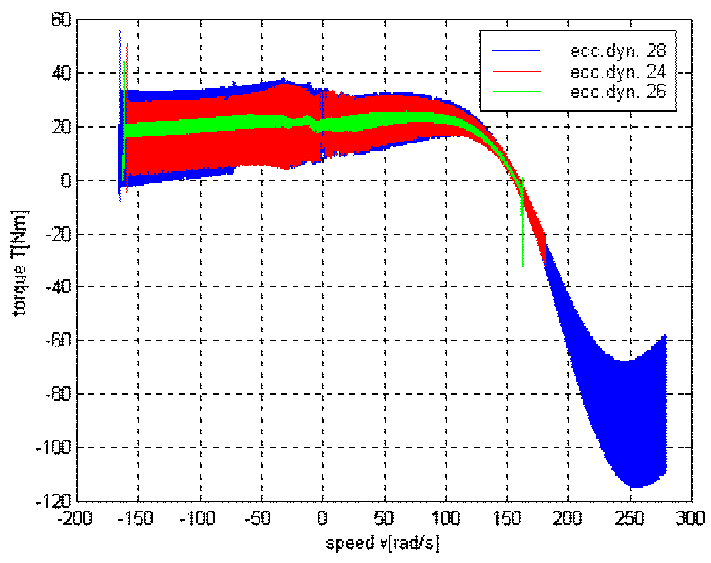

Fig.3. Torque as a function of the speed of the induction motor with $28,26,24$ rotor bars and dynamic eccentricity.

Each dot represents the frequency for which there is a maximum of the absolute value of the torque harmonic calculated at an appropriate value of the speed. The indicated dots were connected to get the graph of the harmonic frequency changes of the parasitic torques. Of course, the parasitic frequency harmonics obtained this way have their share in the values acquired during the simulation. Both the slope of the characteristic of the frequencies of the parasitic torque harmonics and their synchronous speeds can be found in Fig. 1. The synchronous speed was found as the rotational speed at which the parasitic torque harmonic is at the frequency equal to zero. The slope of the characteristics found this way and the synchronous speed in Fig. 1 are collected in Table I.

TABLE I. The sources of the generation of the parasitic torque harmonics

\begin{tabular}{|c|c|c|c|c|c|c|c|c|c|c|c|}
\hline & & & & Tor: & & & & & & Sttar cumert & \\
\hline Item & & \begin{tabular}{|l|} 
Slope of the \\
\end{tabular} & $c_{1}$ & $c_{1}$ & $c_{1}$ & & & & & synchronous speed & amr \\
\hline & 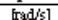 & 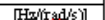 & & & & stator & Rotor & stator & rotor & fagd/s] & \\
\hline la & 22.44 & 4.46 & 2 & 1 & 0 & $\mathrm{lp}$ & $1 \mathrm{p}$ & $\frac{13 p}{13 p}$ & $\frac{1304}{13 p}$ & $\frac{15 y s}{11.22}$ & 1 \\
\hline $\mathrm{lb}$ & & & $=$ & $i$ & 1 & 保 & lp & $13 \mathrm{p}$ & $1 \mathrm{pp}$ & 33.66 & 2 \\
\hline lc & & & 2 & $i$ & 1 & lp & lp & $15 \mathrm{p}$ & $13 \mathrm{p}$ & 11.22 & \\
\hline 2 & -44.8 & 4.46 & 3 & 1 & 3 & lp & lp & $13 \mathrm{p}$ & $19 \mathrm{p}$ & -56.1 & 3 \\
\hline $3 a$ & -112.2 & 4.46 & 4 & 1 & 5 & lp & lp & $13 \mathrm{p}$ & $23 \mathrm{p}$ & -100.98 & 4 \\
\hline $3 \mathrm{~b}$ & & & 4 & $i$ & 5 & lp & lp & $15 \mathrm{p}$ & $25 \mathrm{p}$ & .123 .42 & $s$ \\
\hline 4 & 89.76 & 4.46 & 1 & 1 & 3 & lp & lp & $13 \mathrm{p}$ & $7_{\mathrm{p}}$ & 78.54 & 6 \\
\hline 5 & -44.88 & 8.92 & 6 & 2 & 3 & lp & lp & $29 \mathrm{p}$ & $35 \mathrm{p}$ & 39.27 & 7 \\
\hline 6 & 0 & 13.38 & 7 & 3 & 0 & lp & $\frac{1 p}{1 p}$ & $43 \mathrm{p}$ & $43 p$ & .3 .75 & 8 \\
\hline $7 \mathrm{a}$ & -11.22 & 8.92 & 5 & 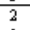 & 0 & lp & lp & $29 \mathrm{p}$ & $29 \mathrm{p}$ & .5 .61 & 9 \\
\hline & & & & & & lp & lp & $27 \mathrm{p}$ & $29 \mathrm{p}$ & & \\
\hline$x$ & & & $s$ & 2 & 1 & lp & $1 \mathrm{p}$ & $29 \mathrm{p}$ & $31 p$ & -16.83 & 10 \\
\hline $8 \mathrm{a}$ & 56.1 & 8.92 & 3 & 2 & 5 & lp & lp & $27 \mathrm{p}$ & $17 \mathrm{p}$ & 67.71 & 11 \\
\hline $8 b$ & & & 3 & 2 & 5 & lp & lp & $29 \mathrm{p}$ & $19 \mathrm{p}$ & 9 & 12 \\
\hline $9 \mathrm{a}$ & -22.44 & 13.38 & 8 & 3 & 3 & lp & lp & $41 \mathrm{p}$ & $47_{\mathrm{p}}$ & -1 & 13 \\
\hline $9 \mathrm{~b}$ & & & 8 & 3 & 3 & lp & lp & $43 \mathrm{p}$ & $49 \mathrm{p}$ & .26 .18 & 14 \\
\hline 10 & -11.22 & 17.84 & 10 & 4 & 3 & lp & lp & $55 \mathrm{p}$ & $61 \mathrm{p}$ & .14 .025 & 15 \\
\hline 11 & .44 .88 & 13.38 & 9 & 3 & 5 & lp & lp & $43 \mathrm{p}$ & $53 \mathrm{p}$ & -41.14 & 16 \\
\hline $12 \mathrm{a}$ & 22.44 & 8.92 & 4 & 2 & 1 & lp & lp & $27 \mathrm{p}$ & $25 \mathrm{p}$ & 16.83 & 17 \\
\hline $12 \mathrm{~b}$ & & & & 2 & & lp & lp & $29 \mathrm{p}$ & & & 18 \\
\hline & -4.49 & 22.3 & 12 & 5 & 0 & lp & lp & $7 \mathrm{pp}$ & $71 \mathrm{p}$ & .2. & 19 \\
\hline $13 b$ & & & 12 & 3 & 1 & lp & lp & $69 \mathrm{p}$ & $7 \mathrm{lp}$ & & \\
\hline $13 c$ & & & 12 & J & 1 & lp & lp & $7 \mathrm{pp}$ & $73 \mathrm{p}$ & & 20 \\
\hline 14 & -44.88 & 17. & 12 & 4 & 7 & lp & lp & $57 \mathrm{p}$ & $71 \mathrm{p}$ & .42 .075 & 21 \\
\hline 15 & $\begin{array}{c}5.44 .00 \\
5.61\end{array}$ & $\frac{17.04}{17.84}$ & $\frac{12}{6}$ & $\frac{4}{3}$ & 0 & $19 p$ & $\frac{1 p}{19 p}$ & $3 p_{p}$ & $37_{p}$ & $\frac{-72.073}{2.8}$ & $\frac{21}{22}$ \\
\hline $16 \mathrm{a}$ & -28.05 & 17.84 & 9 & 3 & 5 & $11 \mathrm{p}$ & $11 \mathrm{p}$ & $4.5 p$ & $5.5 \mathrm{p}$ & .30 .855 & 23 \\
\hline $16 \mathrm{~b}$ & & & & & & $17 \mathrm{p}$ & $17 \mathrm{p}$ & $39 \mathrm{p}$ & $49 \mathrm{p}$ & .30 .855 & \\
\hline 17 & $300 \mathrm{Hzc}$ & netant frequen & 1 & 0 & 3 & lp & lp & lp & $\bar{\gamma}_{\mathrm{p}}$ & const. frequency $350 \mathrm{~Hz}$ & 24 \\
\hline 18 & $600 \mathrm{~Hz}$ & freque & 1 & 0 & 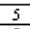 & lp & lp & lp & $11 \mathrm{p}$ & const.frequency $550 \mathrm{~Hz}$ & 25 \\
\hline 17 & $300 \mathrm{~Hz} \mathrm{C}$ & ntart frequency & 1 & 0 & -3 & $\operatorname{lp}$ & lp & lp & Sp & cont. frequency $250 \mathrm{~Hz}$ & 26 \\
\hline 18 & $600 \mathrm{Hza}$ & ntstrt frequency & 1 & 0 & -7 & lp & $1 \mathrm{p}$ & lp & $13 \mathrm{p}$ & const. frequency $650 \mathrm{~Hz}$ & 27 \\
\hline $7 \mathrm{~T}$ & .44 .88 & 4.46 & 2 & 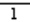 & 1 & lp & Ip & $\frac{15 p}{15 p}$ & $17 \mathrm{p}$ & .33 .66 & 28 \\
\hline 4 & 89.76 & 4.46 & 4 & 1 & .5 & $1 \mathrm{p}$ & lp & $15 \mathrm{p}$ & $s_{\mathrm{p}}$ & 100.98 & 29 \\
\hline
\end{tabular}

To make the harmonics identified this way, more credible, the sources of the generation of these harmonics have been found. They are also collected in table 1 and (in the graphical way) in the analytic/graphic division of the 3-phase machine with 28-phase rotor in Fig. 4.

Harmonics of the electromagnetic torque occur due to the co-action of the stator current with the appropriate harmonics of the magnetic induction in the airgap induced by the rotor currents. How the torque harmonics develop is shown on the diagram (Fig.4), which shows the division of the asynchronous machine under consideration into elementary machines. The sources where these harmonics are generated are collected in Table 1. For example in the case of the harmonic indicated in Table 1 with $1 \mathrm{a}$ input - stator equals to $1 \mathrm{p}$ defines an order of the stator spatial harmonic, which develops particular parasitic torque harmonic. This stator spatial harmonic links itself with the rotor current spatial harmonic designated with input - rotor i.e. also $1 p$ (where $\mathrm{p}$ is the number of motor pole pairs). This harmonic appears itself as the rotor current spatial harmonic with the number of output - rotor i.e. in this particular case as $13 \mathrm{p}$. This harmonic by the co-action with stator current spatial harmonic with the number of output - stator i.e. $13 p$ produces the parasitic torque harmonic under consideration indicated with $1 \mathrm{a}$ in Table 1 . It appears from the Table 1 that the harmonic of the parasitic torque may develop in various ways; e.g. the ways of generating indicated with $1 \mathrm{a}, 1 \mathrm{~b}$, and $1 \mathrm{c}$ all produce this same parasitic torque harmonic, which is identified with its synchronous speed and slope of the characteristic. 


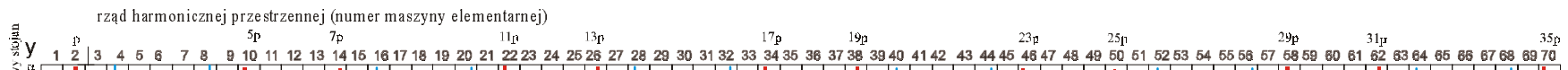

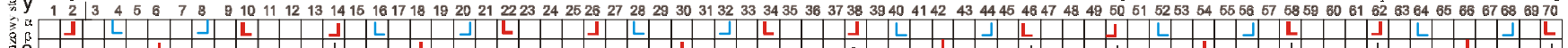

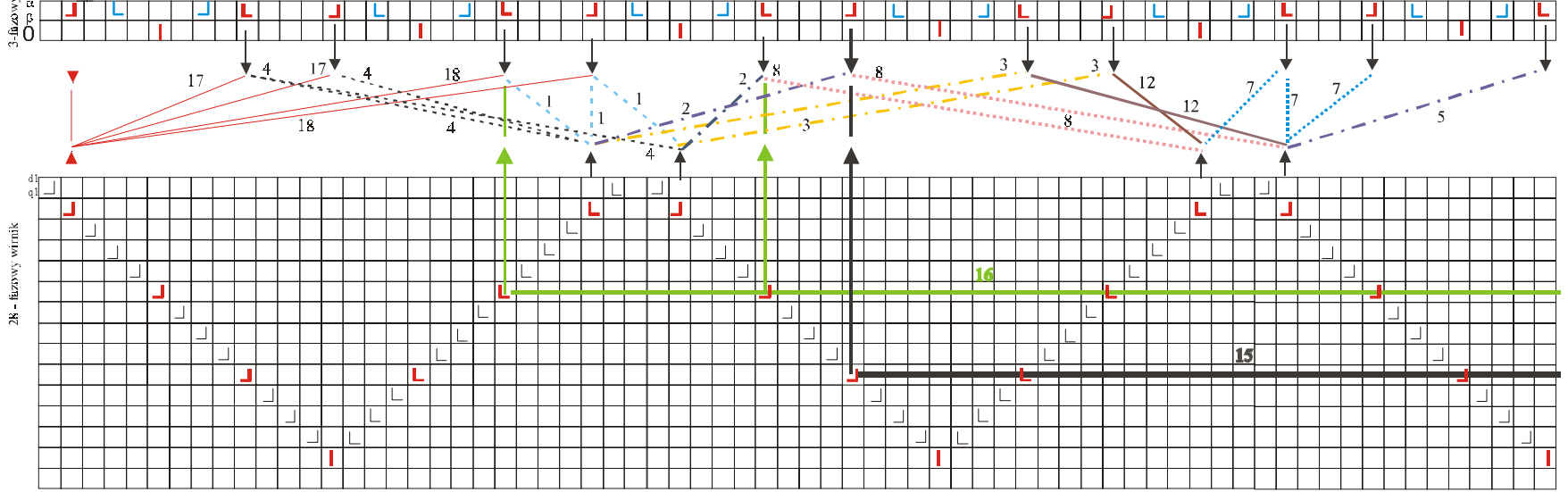

Fig.4. The method of breaking up the 3 phase machine with 28 phase rotor into elementary machines. Lines of generating of parastic torque harmonics are shown on the diagram. The slope of these lines shows these action of the saturation of the magnetic circuit. orders of space harmonics (numbers of elementary machines)

For the calculation of the higher order forces and moment to time for the asynchronous motor has been used Coulomb's method.

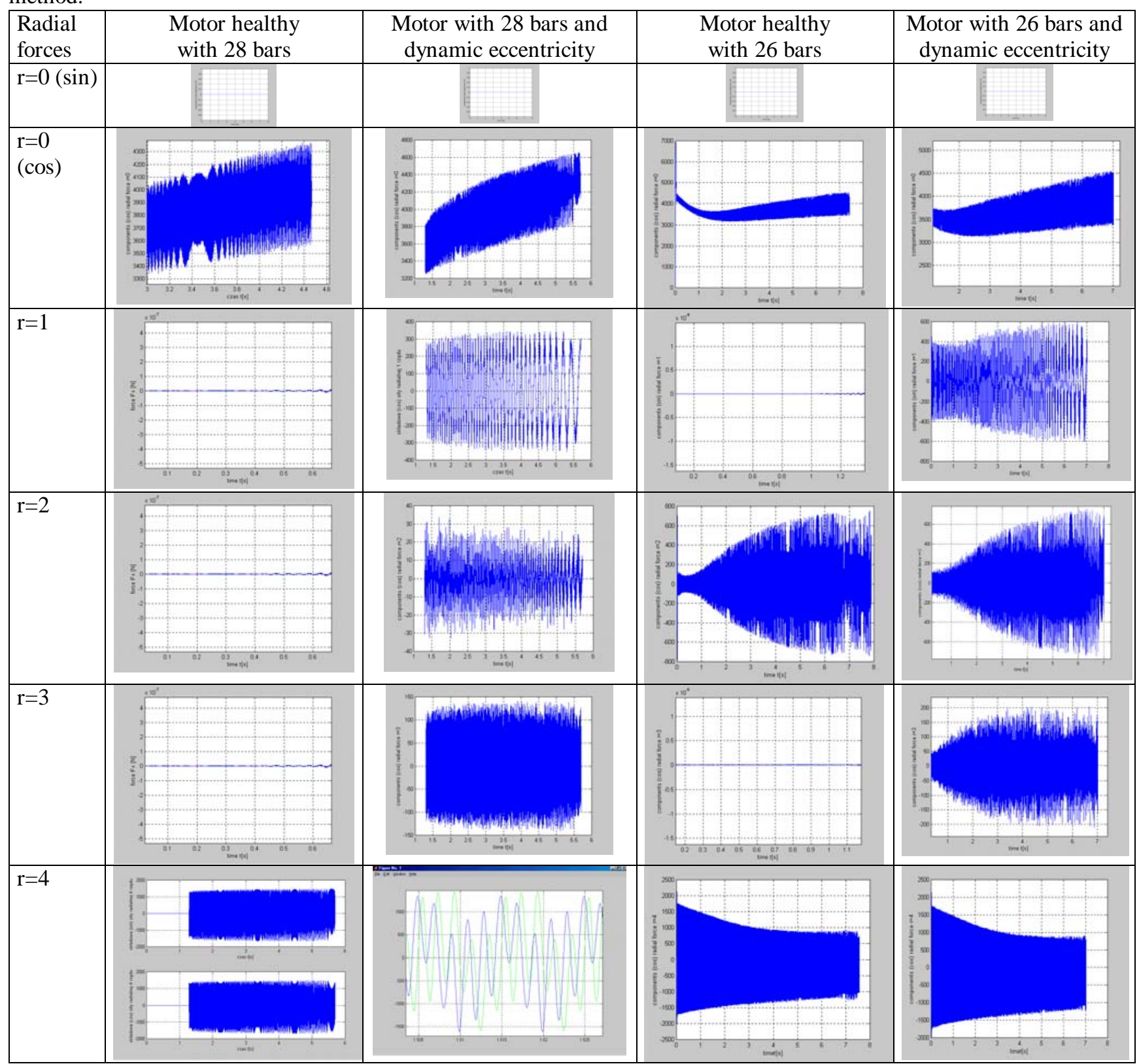




\section{Free vibration analysis.}

To analyse the free vibrations in a more detailed fashion calculations of the rotor model were performed as an addition to the calculations for the model presented above. Calculations of the rotor alone were also performed for other form of its support. A very large stiffness values for the rotor shaft support were assumed [4,5].

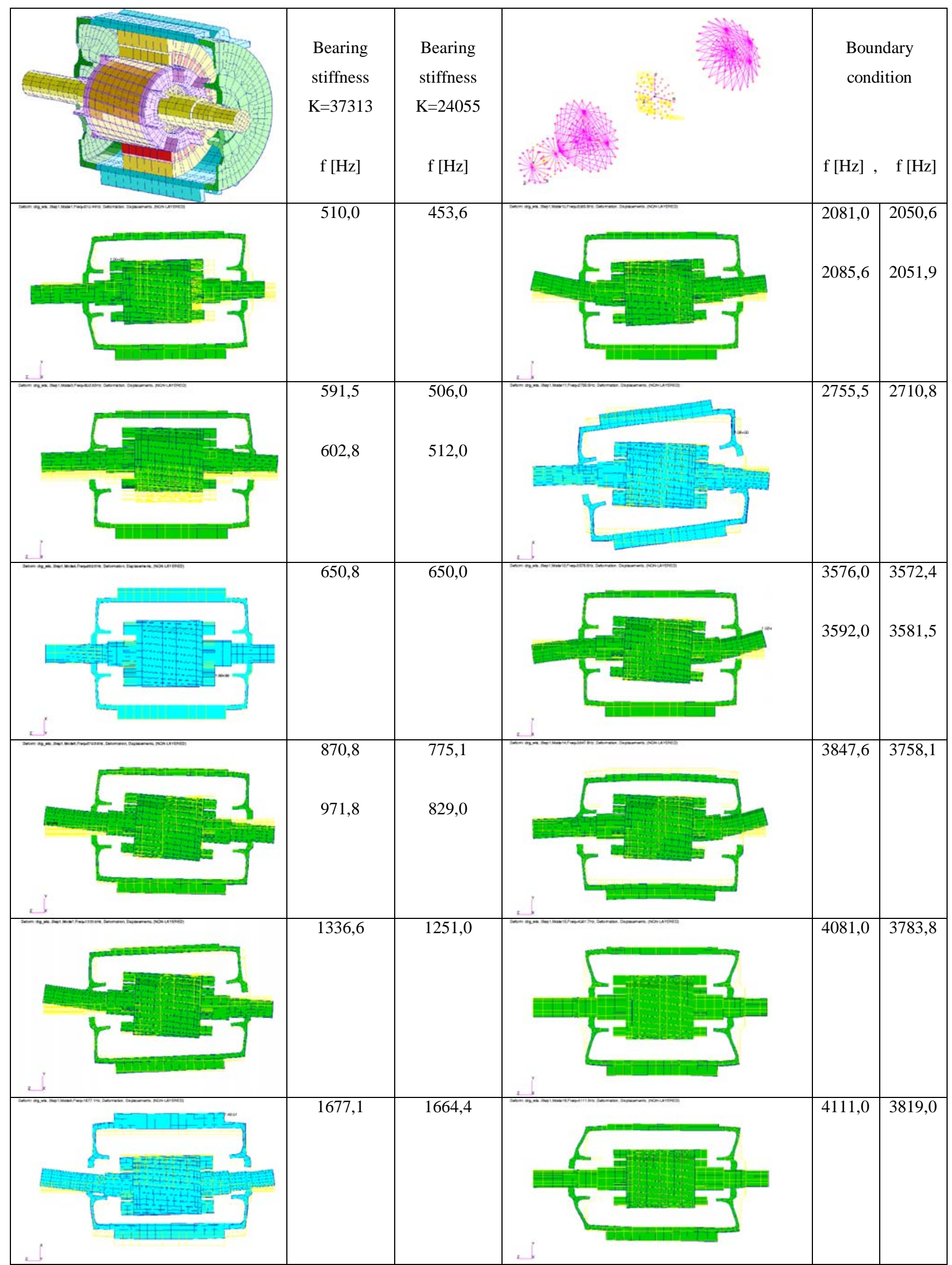




\section{Computational model description}

The mechanical forces result from the rotor unbalance allowances or damages to the elements of rotor bearings. The forces of the magneto-electric origin are due among the others to the change of the length of the airgap between the rotor and stator caused by their misalignment. The alternating forces generated in the rotor can be amplified when to the frequencies of the free vibration of the rotor-stator unit. Thus it is important to know the distribution of the free vibration frequencies for the whole unit. To determine the risky areas of the motor operation it is necessary to perform the calculations of the free vibration frequencies for the whole unit. In the model presented here the rotor shaft complete with core plates and the cage winding. Additionally the model includes also the housing parts complete with two covers, stator core plates and winding elements. The bearings placed in the stator covers were modelled with elastic elements having the appropriate elasticity. Values for the free vibration of such model were determined with finite elements method. The rotor geometry was modelled in the MSC/PATRAN system. To determine the eigen values ABAQUS v5.8 program was used. The calculations were performed in the Academy Computational Center in Cracow, Poland. They were mostly eight- or six-node solid elements. Both rotor and stator of the electric motor were modelled with such elements. Each one of the both rotor bearings were modelled with 3 spring elements (one for each particular degree of freedom). Due to the load applied to a bearing, the bearing raceway and the rolling elements are subject to deformation. These deformations cause the center of the inner bearing ring (placed on the shaft pin) to displace in relation to the outer bearing ring (placed in the motor housing cover). The magnitudes of this displacement depend on the bearing type and size. The displaced magnitudes can be determined with empirical relations. Appropriate MPC Explicite type elements were used to connect the spring elements to the stator and bearing cover. These elements give the option to express a displacement of a particular degree of freedom of one (dependent) node as a function of displacements of particular degrees of freedom of other (independent) nodes. In the model presented here the arithmetic average for displacements of the shaft nodes of one row which lie in the center of the bearing inner ring was assigned to the displacement of one node. Also the displacements of the shaft nodes of one row which lie in the center of the bearing outer ring was assigned to the second node in similar fashion (these are also appropriate nodes from the bearing seat bored in the cover). An elastic element, which links the shaft to the housing, was placed between these two nodes. A separate elastic element was created to for each degree of freedom. This resulted in $6 \mathrm{MPC}$ elements and e elastic elements, three for each bearing. Additionally the model included 20000 of solid elements and 30000 nodes. It is plainly seen from the linearization of the bearing stiffness characteristics that the bearing stiffness decreases as the operation range (of linearization) decrease[1,8,9].

\section{Forced vibration analysis}

Forced vibrations has been simulated by the application of the direct integration method. An input has been, in the form of a concentrated forces, applied in several locations on the shaft. They acted at various frequencies. All these analyses refered to an electric motor so simulated to include motor casing as well as all elastic machine elements. To solve the problem a function acting during 5 periods at the sampling frequency of $1 / 20$ the period.

\section{A. Input through the force acting in the rotor center of gravity}

This arrangement simulates the vector of constant magnitude rotating straight to the shaft axis. Also the case could simulate e.g. the force resulting from the rotor unbalance. Two components; acting along $\mathrm{X}$ and $\mathrm{Y}$ direction respectively have been generated to simulate this condition. Force vectors take the following form:

$\mathrm{FX}=\mathrm{A} * \sin (\omega \cdot \mathrm{t}) \quad ; \quad \mathrm{FY}=\mathrm{A} * \cos (\omega \cdot \mathrm{t})$

where $A=152 \mathrm{~N}, \omega=152,5 \mathrm{rad} / \mathrm{s}$

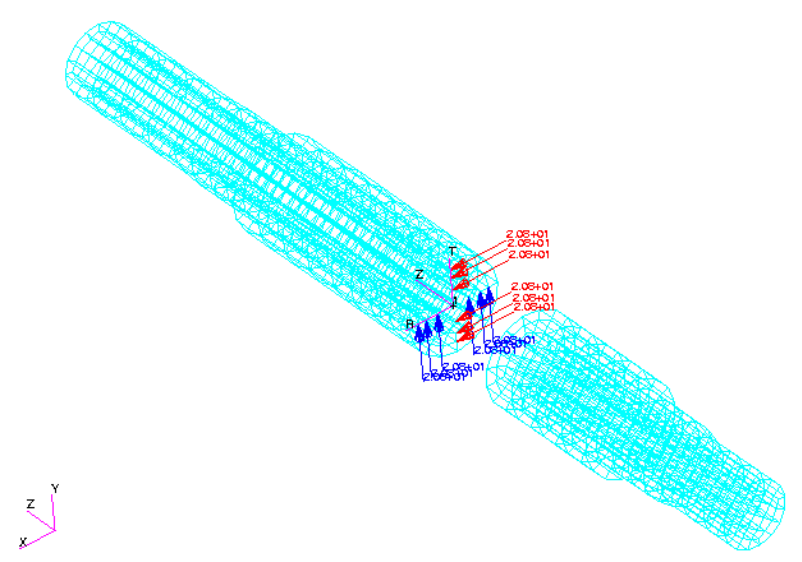

Fig.5. These forces have been applied in 12 nodes placed in the CG's in the manner shown in the following

The resultant force generated by the forces acting over time is a constant vector rotating at constant speed $\omega$. The speed of gyration $\omega$ is related to the shaft rotational speed of 1456,3 rpm $(24,271 \mathrm{~Hz})$.

$\begin{array}{ll}\text { Period duration } & \mathrm{T}=0.04120 \mathrm{~s} \\ 20 \text { period duration } & \mathrm{T}_{5}=0.8240 \mathrm{~s} \\ \text { Integration step } & \mathrm{T}_{\mathrm{c}}=0.00412 \mathrm{~s}\end{array}$

Once the previously described load is applied, the field of variable displacements for the whole structure is obtained. Three representive locations placed in the shaft axis have been selected to analyse the displacements over time. The following locations have been selected: the shaft C.G. (node \# 250133), Shaft center on the right bearing (node \# 251006), and on the left bearing (node \# 251088). The results can be presented in the graphical form. The displacement values have been collected in the Table II. Displacements of these locations for the static calculations have been also shown for the comparison purposes. The dynamic analysis has been performed with the direct integration method and modal analysis. 
TABLE II

\begin{tabular}{|c|c|c|c|c|}
\hline \multirow{2}{*}{$\begin{array}{l}\text { Analysed } \\
\text { location }\end{array}$} & \multirow[b]{2}{*}{ 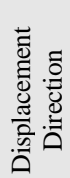 } & \multicolumn{2}{|c|}{ Dynamic calculations } & \multirow{2}{*}{$\begin{array}{c}\text { Static } \\
\text { calculations }\end{array}$} \\
\hline & & $\begin{array}{c}\text { Modal } \\
\text { analysis } \\
\text { method }\end{array}$ & $\begin{array}{c}\text { Direct } \\
\text { integration } \\
\text { method }\end{array}$ & \\
\hline $\begin{array}{c}\text { Rotor center } \\
\text { of gravity }\end{array}$ & $\bar{X}$ & 0,0026 & 0,0026 & 0,00268 \\
\hline Node \# 50133 & $\mathrm{Y}$ & $0,0050^{*}$ & 0,026 & 0,00260 \\
\hline \multirow{2}{*}{$\begin{array}{c}\text { Right } \\
\text { bearing shaft } \\
\text { support. } \\
\text { Node \# 51006 }\end{array}$} & $\mathrm{X}$ & 0,0022 & 0,021 & 0,00220 \\
\hline & $\mathrm{Y}$ & $0,0050^{*}$ & 0,021 & 0,00212 \\
\hline \multirow{2}{*}{$\begin{array}{c}\text { Left bearing } \\
\text { shaft } \\
\text { support. } \\
\text { Node \# 51088 }\end{array}$} & $\bar{X}$ & 0,0022 & 0,021 & 0,00220 \\
\hline & $\bar{Y}$ & $0,0050^{*}$ & 0,021 & 0,00212 \\
\hline
\end{tabular}

Beating-in effect occurred along Y axis.

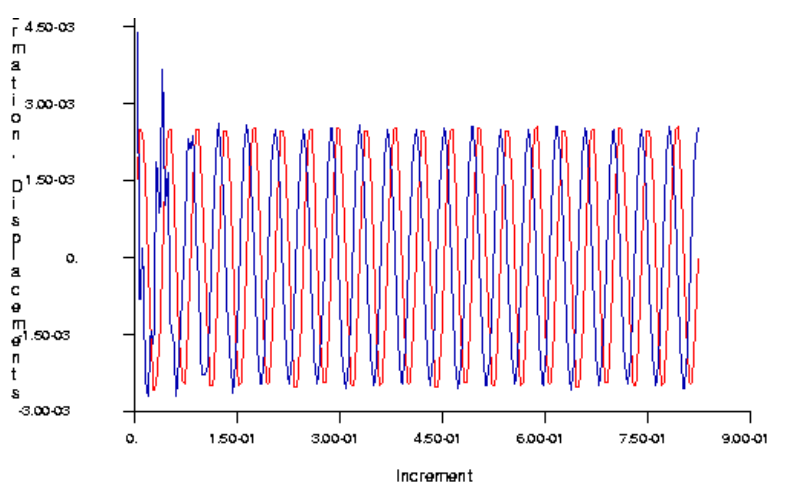

Fig.6. $\mathrm{X}$ and $\mathrm{Y}$ axes C.G. displacement variation. The calculations has been performed with direct integration method.

The calculation results practically agree with those obtained from the static calculations. However the results of the dynamic calculations performed with modal analysis are similar along the $\mathrm{X}$ axis, but they are twice the static values along $\mathrm{Y}$ axis. The beating-in effect occurs here. (Y direction goes vertically).

\section{B. Input through the force acting upon the rotor support}

This case simulates the gyration of constant magnitude vector acting at right angle to the shaft axis. To simulate this condition two components have been generated acting both along $\mathrm{X}$ and $\mathrm{Y}$ axes. Force vectors took the following form:

$$
F X=A * \sin (\omega \cdot t), F Y=A * \cos (\omega \cdot t)
$$

For the calculations it has been assumed that the input forces were of $1 \mathrm{~N}$ magnitude.

$$
\omega=4297,7 \mathrm{rad} / \mathrm{s}(684,5 \mathrm{~Hz})
$$

The input frequency $\omega$ is due to pulses resulting from the failure of a rolling element in the bearing.

Period duration $\mathrm{T}=0.00146 \mathrm{~s}$ 20 period duration $\mathrm{T}_{5}=0.0292 \mathrm{~s}$ $\mathrm{T}_{\mathrm{c}}=0.000146 \mathrm{~s}$

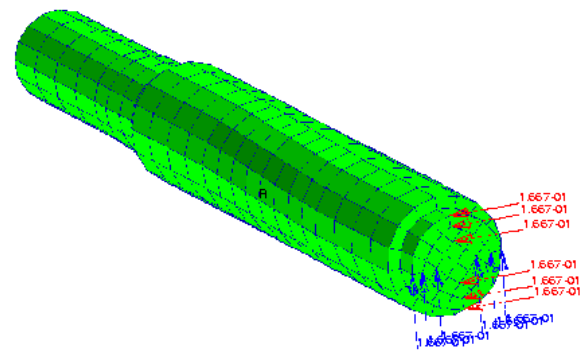

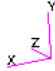

Fig.7. The force components have been applied upon 12 nodes located in the plane bisecting the right bearing of the shaft. The manner of the application of the load is shown in the following:

The superposition of the forces acting over time results in a constant magnitude vector gyrating at constant speed of $\omega$. The displacement calculation results are collected in the Table III:

TABLE III

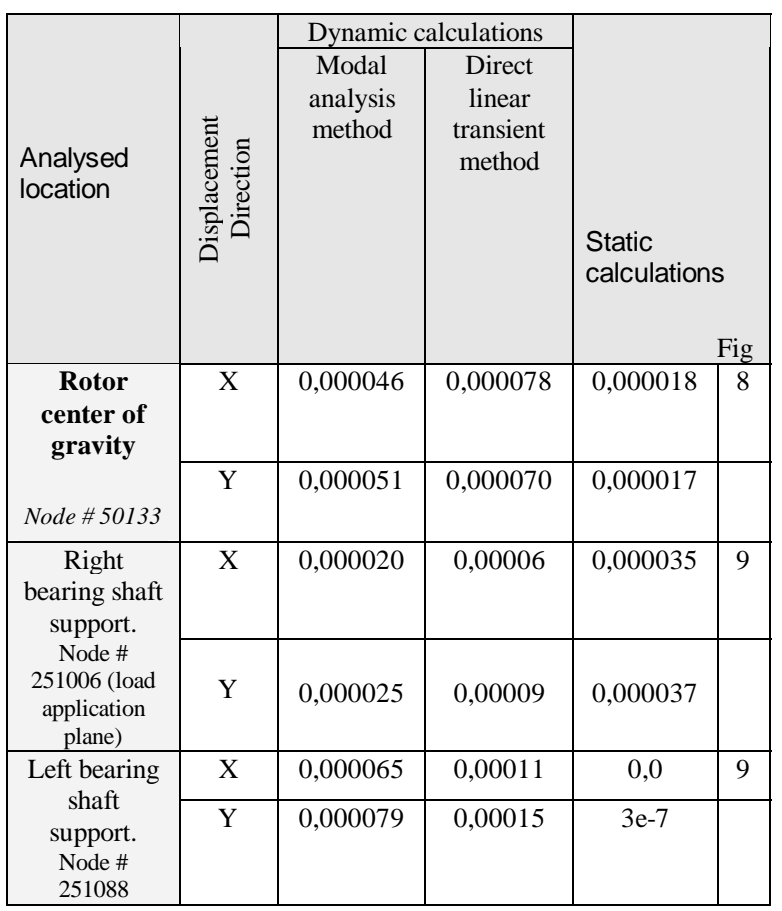
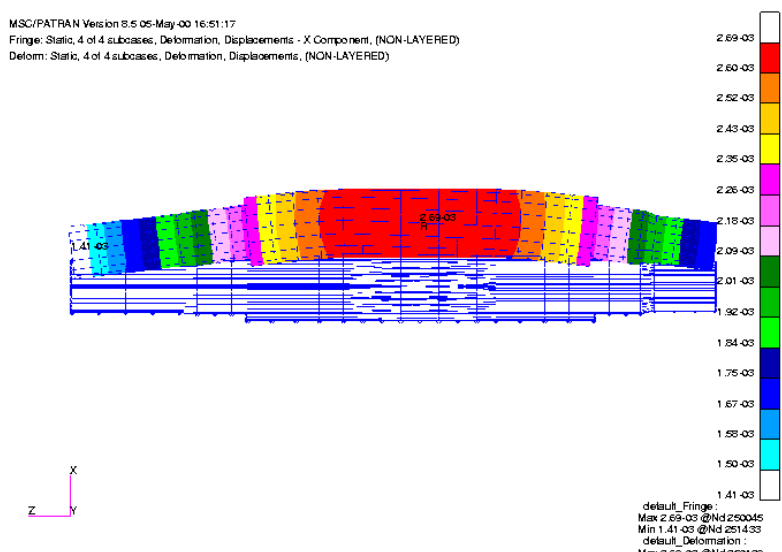

Fig.8. Static calculation for rotor center of gravity Node \# 250133 


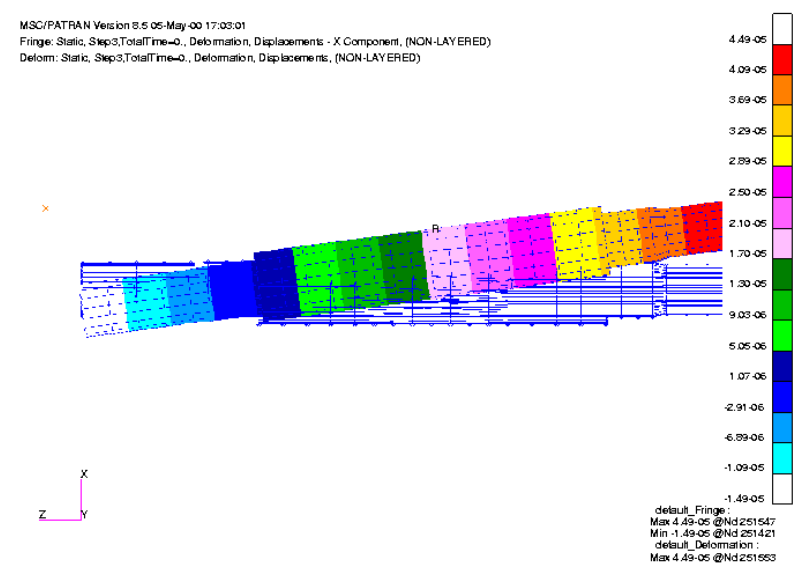

Fig.9. Static calculation for right bearing shaft support. Node \#251006
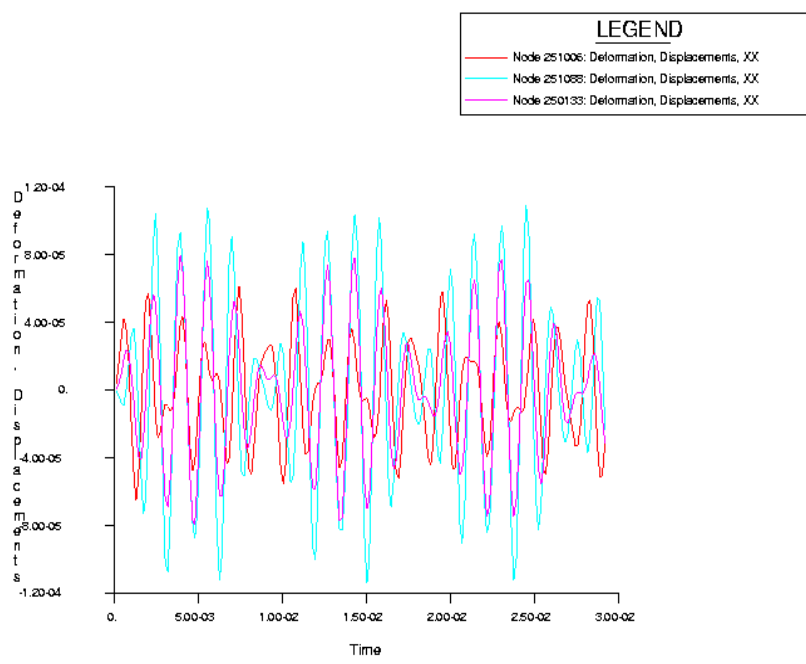

Fig.10. $\mathrm{X}$ axis displacement variation for 3 selected nodes. Direct integration method.
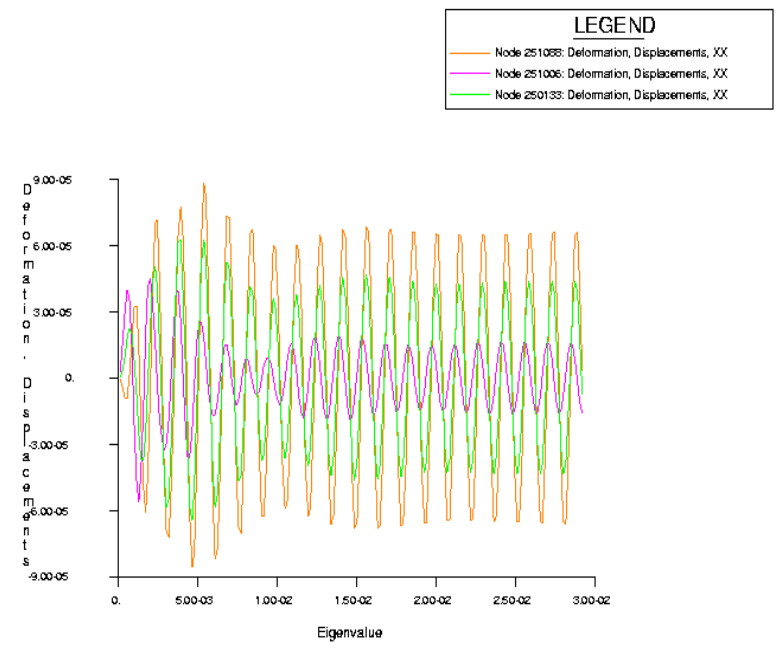

Fig.11. X axis displacement variation for 3 selected nodes. Modal analysis method.

\section{Results of calculations of Fx and Fy forces in time using the FEA 2.5D model of induction motor with static eccentricity.}

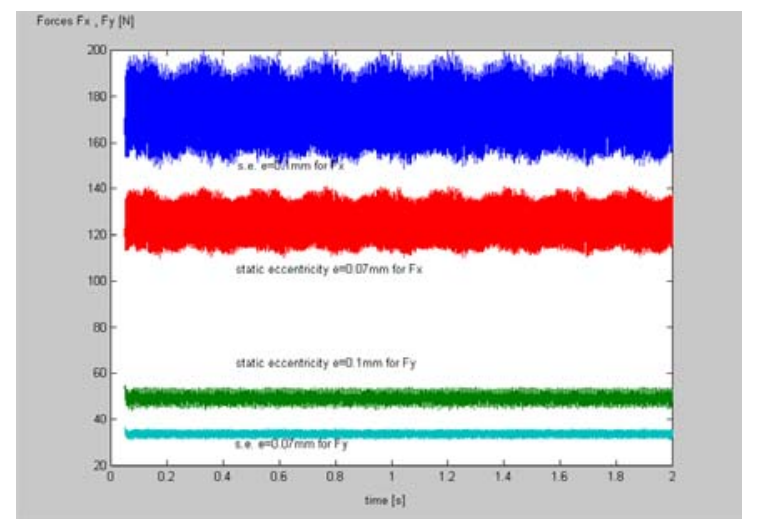

Fig.12. Comparison of the forces Fx and Fy for the motor with static eccentricity $\mathrm{e}=0.07 \mathrm{~mm}$ and $\mathrm{e}=0.1 \mathrm{~mm}$

\section{Conclusion}

The motor under consideration was of Sg90S-4 type due to the rotor bar skew and the stator winding and a number of rotor bars is of low parasitic torques. It appeared though, that the applied numerical model could calculate them. All the harmonics detected in the torque patterns has been confirmed on the ground of the electric machines theory, which was documented in Table 1 and Fig. 1. Starting with the parasitic torque harmonics as known stator current harmonics has been foreseen. The FFT transformation the stator currents were subject to, has supported the correctness of the forecasts. As the analysis has shown hey have their share in generating previously calculated parasitic torque harmonics. The regularity noticed in Table 1 was confirmed this way; any torque harmonic may develop in few ways out of various stator current harmonics, which sometimes could be hardly foreseen "a priori". In the results in Table 1 and Fig. 4 the magnetic circuit saturation in the motor is clearly visible. It among the others produces harmonics of constant frequency which is independent of the speed. The calculated parasitic torque harmonics and stator currents as strongly related. The calculations were performed at ACK "CYFRONET" in Cracow, Poland.

1. The torsional vibration frequency remains practically invariant for various computational models and is $655 \mathrm{~Hz}$ for the rotor model with rigid support in RTZ system and $650.8 \mathrm{~Hz}$ for the model of the whole motor with the rotor supported flexibly in the motor case.

2. The traverse rotor vibrations change according to the model type. The highest flexural frequency shows the model with rotor shaft rigidly supported and it is $2043.8 \mathrm{~Hz}$ in RTZ system, for the model with MPC elements and rigid support it drops down to $1368 \mathrm{~Hz}$, and to $667.6 \mathrm{~Hz}$ when elastic rotor support is taken into account (bearing stiffness $37313 \mathrm{~N} / \mathrm{mm}$ ) and if motor casing with covers is considered in the model the frequency drops down to the value close to $600 \mathrm{~Hz}$. It can be seen that in the most developed model the first flexural frequency is almost three times lower than in RTZ model. Considering the bearing and motor case flexibility leads to the development of simple flexural form of the shaft 
vibrations. In a developed model of the motor the flexural forms odf the vibrations of the shaft superimpose over the displacements of the bearing shaft supports as well as bearing covers displacements, which creates even more complex flexural forms of the shaft vibrations.

3. It can be seen that in the transverse vibrations at $602.8 \mathrm{~Hz}$ the major share has the bearing support stiffness. It is worth to note that the displacements on both supports are in the same phase, but at the $870.8 \mathrm{~Hz}$ frequency the displacements in the bearing supports are in counter-phase. At the frequency of $1336 \mathrm{~Hz}$ also the displacements in the motor casing add up to the overall displacements. At the $1667 \mathrm{~Hz}$ frequency displacements of the shaft alone and in the shaft supports are in counter-phase to the displacements of the case. At the frequency of $3576 \mathrm{~Hz}$ the rotor shaft vibrates at II harmonic. At frequencies of $1667,4081.7,4111 \mathrm{~Hz}$ the share of the case vibrations becomes more prominent, and at $2775.5 \mathrm{~Hz}$ - the rotor vibrations [10].

4. After the consideration of various electric motor models one can come to the conclusion that taking into account that shaft support conditions which closer to the actual ones decreases significantly free vibration frencies and develops even more complex rotor vibration forms.

5. Forced vibration calculations performed with the direct integration and modal analysis methods. The case when input is effected by gyrating force applied in the rotor center of gravity. The simulations of the vibrations influenced by the rotor unbalance have shown that both static and dynamic displacements obtained during the analysis were the same. It seems that the dynamic boost influence is insignificant.

6. Forced vibrations analysis. The simulations of the bearing failure in the right support have shown that the displacement of the free shaft end is two times greater than the shaft displacement for the location where the load is applied. In the case of direct integration they are almost 4 times greater than the static displacements. There occurs such significant increase in the dynamic displacements occurs because the input frequency is very close to free form vibration frequency of the system.

\section{References}

[1] A. Arkkio, "Unbalanced pull in a high-speed induction motor with an eccentric rotor", ICEM'94

[2] J. L. Coulomb, „A methodology for determination of global electromechanical quantities from a finite element analysis and its application to the evaluation of magnetic forces, torques and stiffnes", IEEE Trans.Magn., vol.19,pp.2514$2519,1983$.

[3] T. Glinka, "Diagnostics of the winding insulation of electrical machines using a constant voltage", Electrical Technology Russia, no.1, 1998, pp.31-37. Publisher: ZNACK, Russia.

[4] B. Heller and V. Hamata, "Harmonic field effects in induction machines" Academia, Publishing House of the Czechoslovak, Prague 1977.

[5] G. Kamiński and W. Przyborowski, "Uzwojenia i parametry maszyn elektrycznych", Oficyna Wydawnicza PW., Warszawa 1998.

[6] K. Kluszczyński, "Momenty pasożytnicze w indukcyjnych silnikach klatkowych", PTETiS, Warszawa-Gliwice 1993.

[7] M. Noga, L. Golębiowski and D. Mazur, "Calculation of rotor defects of the induction motor using FEM", HIPER'98, October 14-16, 1998, Zurich, Switzerland.

[8] K. Pawluk and T. Schweitzer, "Application of magnetic field analysis methods to calculations of electric machines", Przeglad Elektrotechniczny, vol.72, no.8, 1996, pp.193-9.

[9] J. Penman and A. Stavrou, "Broken rotor bars: their effect on the transient performance of induction machines", IEE Proceedings. Electric Power Applications, vol.143, no.6, Nov. 1996, pp.449-57.Publisher: IEE, UK.

[10] W. Rams, J. Rusek and J. Skwarczynski, "Forces acting on induction machine stator core due to winding faults", Archiv fur Elektrotechnik, vol.76, no.3, 1993, pp.219-24. Germany.

[11] J. Rusek, "Reflection of eccentricities in spectral composition of currents of induction machines", ICEM96 Proceedings. International Conference on Electrical Machines. Univ. Vigo. Part vol.2, 1996, pp.470-5 vol.2. Vigo, Spain.

[12] S. J. Salon, „Finite element analisis of electrical machines”, Kluwer Academic Publishers, Boston /London/ Dordrecht, 1995.

[13] WT. Thomson and A. Barbour, "On-line current monitoring and application of a finite element method to predict the level of static airgap eccentricity in three-phase induction motors", IEEE Transactions on Energy Conversion, vol.13, no.4, Dec. 1998, pp.347-57 